\title{
How can an Online Community of Practice support New Teacher Development?
}

\author{
Adam Unwin, \\ UCL Institute of Education, United Kingdom
}

\begin{abstract}
This research concerns the professional development of teachers in their first year of teaching who were studying the Master of Teaching (MTeach). The research was interested in the views and experiences of the teachers' participation in the online discussions (ODs) and how this helped them develop. The findings are that the ODs enabled new teachers to participate by writing for an audience of peers, and by providing a sense of community, with an underlying practitioner focus developed their criticality. These new teachers developed a collegiality, reflexivity and an engagement with wider and longer term perspectives. The research concluded that the gains from the ODs were the result of careful pedagogic design. The overarching finding is that by foregrounding the situated experiences and interests of the teachers, a 'way in' is provided for them to understand more fully the complexities, dilemmas and strategies encountered in their own and others' professional practice.
\end{abstract}

\section{Introduction}

The Master of Teaching (MTeach) course was designed in 2000 to focus on the development of teachers in the challenging early phase of their teaching careers [4]. These were made up from teachers from different schools, phases (primary and secondary) and subjects. The then DfES recognized that this new course aimed to provide a framework of 'support for talented new teachers in urban schools'[5] encouraging high level professional learning to take place, nurturing an enquiry approach to 'understanding teaching' and raising levels of 'research literacy'.

The context is important: these are new teachers are vulnerable to heavy workloads and tend to be time poor. They have views on pedagogy and they are situated in schools with day to day experiences and concerns which they need to draw on, share and make sense of if their development is to be meaningful.

There are three main pedagogic ideas that illustrate the thinking behind what the MTeach is trying to achieve and the way it operates. First, there is a clear focus on the participants' own teaching, their students, their classrooms and their schools. It is a starting point for them to engage critically with practical and theoretical educational issues by trying to make sense of their situated practice [12]. Secondly, it is about participants communicating and reflecting on their own and each other's practice. It is believed that this sharing and explaining of their experiences and ideas will not only deepen understanding of the complexities at play in teaching but also encourage reflexivity and analysis. What is important is that this communication fosters the development of a 'community of inquiry' [7] [8] within the online groups.

'...a community where individual experiences and ideas are recognized and discussed in light of societal knowledge, norms and values' [7]

This links to the third pedagogic idea that concerns the development of a deeper understanding of the role of research in education. This is not only about exposure to wider debates about teaching and learning than they might experience in their schools, it is also about them critically evaluating or 'researching' what is happening in their own classrooms.

The course is 'mixed mode' in the sense that both face to face (f2f) sessions and online components are used. An influential factor in adopting this approach is that the participants (mostly early career teachers) are in a demanding phase of career development where the logistics of 'traditional' f2f study could be a barrier. By using the potential of learning technologies the course can be undertaken in a more flexible way by participants who are often in contexts where they have to juggle competing professional and personal priorities. This foregrounds an overarching concept of pedagogic design that is explored in this research. It concerns how the pedagogic design of the MTeach ODs underpin and enable new teacher development?

\section{Technology and Education}

There is a tendency to assume educational benefits when introducing technology to the learning process without taking a critical and analytical 
perspective to what is actually happening and why this might improve (or not) the learning process [14] [16]. A lack of critical engagement with theoretical and pedagogic issues will potentially result in short term surface level learning when adopting new technologies. This is particularly likely at a time when many (politicians, managers, software developers) see 'downloadable education' as cost effective (and profitable), teacher-proof (and a tool for monitoring/target setting). Virtual Learning Environments (VLEs) can all too easily become a content depository of files, resources and PowerPoint presentation packages encouraging 'transmission' approaches and potentially reducing interactivity. Laurillard neatly summarizes this as "How do we ensure that pedagogy exploits the technology, and not vice versa?' [11].

The issues raised here are important for this research context. The thinking behind the MTeach is to utilize the participants own professional teaching experiences as a critical 'way in' to the topics and issues covered by the course. The challenge has been to develop appropriate pedagogies for the online elements of the course. Rather than be constrained by the technologies and the pedagogies they might encourage, the idea is to utilise affordances the new technologies might offer. The research is examining this use of technology and the implications for teacher learning.

\section{Data and Analysis}

The data gathered for this research was from five successive cohorts of new teachers. This included their accounts of participation in the ODs, written towards the end of the first year of teaching and interviews conducted with a selection of these teachers at a later stage in their career. Using this data enabled the research 'to gain access to their accounts and articulations '[13]. The research was guided by the main question: how have the ODs facilitated new teacher development within the context of the MTeach? The theoretical perspective adopted for this research was interpretive with a methodological approach that used qualitative data. Coding utilized qualitative data analysis software (NVivo) and analysis was assisted via 'thick descriptions' [3]. Table 1 provides a summary of the themes that emanated from the research.

The themes can be considered outcomes of the ODs whereas the term 'pedagogic design' is used to refer to the strategies and processes that facilitate the ODs. It is about what participants were asked to do as part of the OD and how this was structured, set up and worked. The research process adopted the lens of pedagogic design to help understand better what was happening within the ODs.
Table 1. Theme summaries

Community: It was apparent that participants felt that elements of community developed during the MTeach and that the ODs helped facilitate and sustain this community. This is something that sometimes contrasted with their experiences in school or was an additional support network for them. The value of these communities manifested itself in participants feeling less isolated, feeling safe, being able to honestly share and compare experiences in a non-judgmental way, feeling trust and being empowered and more confident about their teaching strategies.

Practitioner focus: The ODs enabled a practitioner focus where participants could share information and experiences and seek advice. This centered on what was happening at school, in their department, in their classroom, with groups and with individual students. Often this involved discussing relatively short term issues and ideas but there was clear evidence of longer term strategies starting to develop and be considered important. These practical issues were not only about their classes and teaching but also about wider early professional development (EPD) matters such as support and power relations.

Criticality: It was apparent that participants developed their skill of criticality. They were aware of this during their participation in the ODs, on reflection at the end of their newly qualified teacher (NQT) year and later when interviewed. This criticality took a number of forms. It was about: questioning the status quo and practice; self-criticism / reflection; thinking deeply about what was happening and why; recognizing the complexities involved; seeing links between theory and practice; questioning theory and seeing a bigger picture (beyond school).

Writing (and reading): Because the ODs are conducted as asynchronous text based exchanges it is unsurprising that participants found the integral reading and writing important aspects of the ODs. This theme considers these aspects but also looks at what participants felt the writing enabled or restricted within the ODs as well their wider thinking. For instance, how did the need to be succinct and present personal contexts and thoughts clearly to others help participants?

\section{Summary of research questions and research findings}

The overarching research question is 'How have the ODs facilitated new teacher development within the context of the MTeach?' The findings suggest that the ODs provided an environment and activities where participants developed a sense of community. This community allowed a safe space for them to 
share their practical experiences and concerns about their teaching and school lives. This participation with other new teachers provided support and development different from that in their school settings. The use of the ODs encouraged a deeper, wider and more critical understanding of participants' classrooms. This is because the ODs were designed to make use of literature, have tasks that require reflection, and to frame discussions around participants' own classroom experiences and responses to peer experiences.

'What is the nature of new teacher development within this setting?' was one of the sub questions. Analysis suggests that there was development within the groups and as individuals of 'criticality'. This was a gradual development over time as participants used the ODs to look at their classrooms and situated experiences in different ways. Their participation included questioning literature, practice and policy and the adoption of an inquiry approach to situations and issues. This development was not phase or subject specific but seemed to foster transferability and adaption of ideas to participants' professional practice as well as consideration of wider perspectives. This criticality included recognition of the complexity of factors at play in education and the limitations of short term and 'quick fix' solutions or strategies.

'What aspects of the OD do participants see as important in enabling new teacher development?' was the second sub question. It was clear that participants valued the community made up of similar (all new) but different (schools, phases and subjects) teachers, where they felt they could be honest and open. The practitioner focus was important with the starting point for the ODs being their own classrooms and issues of concern and interest to them. This practitioner focus along with the structure and timing of the ODs made it manageable in the very busy first year of teaching. The requirement to write succinctly and for an audience of peers was both difficult and beneficial. It was difficult to convey contexts as clearly as face-toface (f2f) discussions where an explanatory and clarifying dialogue can occur. The process of writing for the ODs made participants think carefully about their contexts and made them analytical about their practice and situation.

'How does the pedagogic design of the ODs underpin and enable new teacher development?' was the final sub question. It is clear from the analysis that the pedagogic design of the ODs was key in facilitating the way they worked. This could be described as happening at both a macro level (course / module) and at a micro level (OD specific). For example, macro factors would include the length of the module over a whole academic year, with a mix of half-termly ODs and termly f2f meetings. Also, that online tutor groups were small (no more than 15) and made up of a mix of phase and subjects teachers, whereas micro factors concern how the specific halftermly activities were designed: that literature was introduced with a concise briefing paper that set out the required focus in an accessible way; that ODs used frameworks, models and tasks to help participants think about issues in their own classrooms; that ODs required the starting point to be something that was part of each participant's situated experience; and that there were clear, manageable timelines and word limits.

\section{Limitations}

It is important to acknowledge that using ODs as a central element of a course will not be without its difficulties. It was apparent participants did not have much previous experience of formalised online courses, much less using asynchronous discussion groups. Since these students are new teachers, focussed on $\mathrm{f} 2 \mathrm{f}$ learning as practitioners themselves as well as in their studies to date, it is unsurprising that their views on the ODs include comparisons with f2f study. It was clear that the early stage is crucial for community formation, gaining an understanding of what is required and developing confidence and criticality. Written communication has limitations, with reduced opportunities to unpick, clarify and understand the nuances of different contexts in comparison to some f2f activities.

\section{Reflexivity}

What is significant about the MTeach ODs is that, despite the presence of pressures and barriers to deeper thinking, they allow and encourage reflexivity. The online tasks and activities ask participants to reflect on their practice, but not in a narrow, prescribed or formulaic way. The ODs require participants to explain and share their teaching contexts. By doing this these experiences are moved into a more public realm encouraging collective reaction and responsibility. So rather than being inward looking with a danger of self-blame, the complexity of the classroom and the need to consider wider perspectives is foregrounded as valid and important. These teachers are at the very beginning of their teaching career with pressure to 'get things right' quickly (control behavior, meet induction standards). In contrast to this the ODs provide a more gradual approach and encourage longer term thinking to help them understand what is happening in their classrooms. Participants adopted a sustained evaluation of practice, revising their views and ideas as the year progressed. This was facilitated by being part of a community that exposed them to different practice and different ways of looking at practice, and the enquiry approach that was required within ODs and module coursework. 
This inquiry approach encouraged deeper, wider and forward thinking about practice rather than narrow, individualistic reflections about what has happened. These new teachers were starting to make what Moore called the 'reflexive turn' [15] becoming 'authentically and constructively critical ...challenging rather than confirmatory' [15]. They were experiencing a 'pedagogy of discomfort' [2] where their educational assumptions were challenged by themselves and each other. There is a sense that their evolving identities as teachers were linked and shaped by the MTeach and the ODs. It is the shared critical discourses, particularly within the ODs, that influence their thinking and practice at this early stage of their teaching career. Reflexivity recognizes the importance of community, collaboration and collegiality which is discussed in more detail below.

\section{Collegiality}

According to the findings, what is special for new teachers on the MTeach is that they have a space separate from work where they can raise issues of concern and interest and this is in a community of equals or peers. For example, they can question school policy or micro-community practice without feeling vulnerable, judged and compromised. They can also be honest and explicit about their progress, what they fear, what has gone wrong, what has gone well, what they find frustrating and other challenges. In the ODs they are 'listened to' and receive feedback about issues specific to them and their context which provides a supportive community with a semi-cathartic role. This collegiate process is underpinned by the way the ODs are designed, where participants initially present to the whole group issues (albeit framed within an area of focus) that are of contemporary interest to them. They subsequently receive feedback from others with threads of discussion often developing. What makes this process more empowering (and perhaps less threatening) is that the online group has the added dimension of an inter-subject and inter-phase collegiality, with participants benefiting from understanding beyond their school or subject microcommunity. In the ODs teacher professional judgement is allowed and valued; by developing their criticality in this way at this early stage of a teaching career attributes of reflexivity are nurtured.

What is important is that the collegiality that the ODs facilitate is not confined to the MTeach group; if it were it would be limited in terms of teacher development. What happens is participants' critical engagement with practice becomes integrated into their school contexts and communities. Participants explained how the development they gained via the MTeach was different from their experiences at school. They were often complimentary about aspects of school support, feeling that the MTeach supplemented this and gave them wider perspectives: neatly summarized by one participant as the 'why' not the 'how'.

Yandell [19] when discussing student teachers' school experiences draws on Lave and Wenger's [12] work explaining how peripheral participation and overlapping communities of practice can be difficult but provide a 'privileged vantage point'. 'These are not necessarily comfortable relations, and there are frequently tensions and contradictions both within and between intersecting communities of practice.' [19] He goes on to say '...peripheral participation can also be a privileged vantage point, a position from which to make sense of the hurlyburly...' [19]

This resonates with what is happening for the MTeach participants, they are new teachers and they are subject to competing pressures and expectations within their school communities (where they are novices). They also are undertaking the MTeach and becoming part of that community which is facilitated by the ODs (between peers). The participation within this overlapping community of practice gives them both support and the confidence to look at what is happening in their schools and classes in alternative and critical ways. Their participation in the MTeach strengthens their school roles, giving them the selfassurance to suggest and introduce new ideas; contributions which were often recognized as valuable and acted upon. Thus the practitioner focus and criticality that are intrinsic parts (and are outcomes) of the MTeach ODs gives credibility to the participants in their school communities.

\section{Presentism}

The concept of presentism drawing on Hargreaves' work on 'the persistence of presentism' [7] was central to this work. Hargreaves identifies an over reliance on short term strategies which is in part due to a constant flow of policy initiatives and pressure for results. There is a concern that new teachers will adopt a survivalist approach [18] and concentrate on the immediate, especially if such short term strategies are part of school ethos and practice. In a similar way to utilizing competence based standards this short term focus will limit the development of reflexivity, of thinking more deeply about the complexities and longer term issues at play. There is the danger the strategies provided are 'one size fits all' and that new teachers are expected to implement these in a prescribed way, rather than the teacher experimenting with strategies that 'encourage teachers to question and revise their existing approaches to teaching and learning' [10]. They will be working in an environment where there are expectations to 'fit in' and 'perform' from school communities (e.g. subject) and management. Haggarty et al. [9] find that new teachers are 
expected to 'master behavior management' and work to the norms of the school, which stymies any real development of pedagogical thinking and practice.

The concept of presentism chimes with work by Ball [1] on the growth of performativity in education in part exacerbated by neo-liberal agendas and marketization. Hargreaves [10] suggests that presentism can be addictive and become endemic, whereas in the case of the new teachers on the MTeach the ODs are a crucial factor in reducing such tendencies. The criticality and practitioner focus central to the ODs counter and challenge presentism. The way the ODs are structured and evolve allows these teachers a longer time frame to engage in a more nuanced consideration about their teaching. The situated nature of the initial stage of the ODs foregrounds and requires thinking about context appropriate rather than standardized 'quick fix' strategies. The process of writing for an audience of peers provides a source of Hargreaves' deeper 'rumination or reflection' [10] where participants need to think analytically about what is happening in their teaching and then present this in a meaningful and succinct way to peers. The community and situated aspects of the ODs exposes these new teachers to different ideas and accounts of practice which by design often become focused on particular learners. This challenges the assumption there is one way or a best way of doing something when it is apparent that contexts and learners can be so diverse.

\section{What about the technology?}

There are a number of ways technology assists what happens on the MTeach. For example, participants have flexibility to access materials and work on activities from a distance when it suits them (within certain structures and timelines). The technologies we use influence the pedagogic design, for instance we decided to use an asynchronous discussion forum for the ODs. These asynchronous discussions work within the overall aims of what we want the ODs to achieve: allowing participants to utilize their own and each other's professional teaching experiences as a critical 'way in' to the topics and issues covered by the course. It is the course team that makes decisions as to how to use them (timings, structures, requirements) and these are pedagogic decisions. This research has confirmed the importance of not being constrained or pushed in a particular direction by the technologies. Rather, there is a need to develop approaches that utilize the affordances technology offers to achieve the desired pedagogy.

More specifically with teachers in mind Fisher et explain how teacher learning is complex, multifaceted and 'resistant to standardization' [6] but there are 'affordances' digital technologies can offer to enhance teacher learning. They provide a framework for categorising and describing these concepts and activities.

Table 2. Clusters of purposeful activity with digital technologies [6]

\begin{tabular}{|c|c|}
\hline $\begin{array}{l}\text { Knowledge } \\
\text { building }\end{array}$ & $\begin{array}{l}\text { - adapting and developing ideas } \\
\text { - modelling } \\
\text {-representing understanding in } \\
\text { multimodal and dynamic ways }\end{array}$ \\
\hline $\begin{array}{l}\text { Distributed } \\
\text { cognition }\end{array}$ & $\begin{array}{l}\text { - accessing resources } \\
\text { - finding things out } \\
\text { •writing, composing and } \\
\text { presenting with mediating } \\
\text { artefacts and tools }\end{array}$ \\
\hline $\begin{array}{l}\text { Community and } \\
\text { communication }\end{array}$ & $\begin{array}{l}\text { exchanging and sharing } \\
\text { communication } \\
\text { - extending the context of activity } \\
\text { - extending the participating } \\
\text { community at local and global } \\
\text { levels }\end{array}$ \\
\hline Engagement & $\begin{array}{l}\text { - exploring and playing } \\
\text {-acknowledging risk and } \\
\text { uncertainty } \\
\text {-working with different } \\
\text { dimensions of interactivity } \\
\text {-responding to immediacy }\end{array}$ \\
\hline
\end{tabular}

The MTeach uses technology to facilitate the ODs by providing a forum (the online tutor group) and various digital artefacts and resources. What is evident from the research is that the ODs achieve to varying degrees' purposeful activities from all clusters. It is the community and communication cluster that features strongly and this facilitates the development of activities in the other clusters. For example, the way the ODs are set up requires teachers to participate within a community, to share and exchange information, which in turn leads to activities such as 'adapting and developing ideas' and 'writing, composing and presenting' from the other clusters.

Fisher et al [6] suggest that professional development will benefit by 'designing in' (author words) community and communication. 'The community and communication affordances are exploited as teachers reflect upon their practice within a wider community. They can use communication tools to engage in reflective analysis of materials and experiences with colleagues and mentors, and such opportunities for reflection, both on general practice and the use of ICT in their teaching, need to be built into and prioritised in the design of professional development schemes and innovations.' [6]

This concurs with what this research has found on the MTeach. The ODs use the technology to allow participants to share their reflections and experiences. The pedagogic design behind the OD considers carefully where these teachers are situated 
and the pressures they are under. Providing communication tools in itself is not enough; the communication expectations need to be realistic. Early in their paper Fisher et al encapsulate what they feel is needed for teacher learning to be successful.

'Teachers learn and develop their professional knowledge best when the aims and purpose of activities are relevant and authentic to their own lives; when they can use a variety of tools to help them realise and express their goals; and when they are in relationship with others in the wider community which shares rules and ways of working' [6]. Again this resonates strongly with the pedagogic design that enabled such processes within the MTeach ODs.

\section{Conclusion}

What is important in the way the ODs operate is that they endorse an engagement with the 'complexity of the classroom' [17] and in doing so question simplistic solutions or strategies. They foster an enquiry approach, which by its nature is forward thinking and moves away from the immediacy of presentism. This future orientation means strategies become longer term, more holistic and grounded in why things happen as opposed to adopting approaches which are judgmental, formulaic and over focused on the negative. This forward thinking and enquiry although concerned with participants' own contexts, are assisted by the community and by the artefacts that make up the online activities. These have an important formative role and demand engagement with theoretical concepts and wider perspectives that go beyond their subject, phase or school context.

New teachers are vulnerable to presentism; it can become part of a survivalist strategy especially if promoted within the school ethos and practice. The way the ODs are designed, the way they operate, the multi-faceted contexts of participants and the actual outcomes (the discussions) are all important in making them work in a way that counters the beguiling attraction of presentism. This combination of factors encourages a questioning a 'reflective skepticism' towards new initiatives, policy and best practice models rather than a passive acceptance.

\section{References}

[1] Ball, S.J., (2003) The teacher's soul and the terrors of performativity', Journal of Education Policy, Vol.18 (2), pp.215-228.
[2] Boler, M. Feeling Power: Emotions and Education. Routledge, New York and London, 1999.

[3[ Creswell, J. and Miller, D. 'Determining Validity in Qualitative Inquiry Getting Good Qualitative Data to Improve Educational Practice'. Theory into Practice 39 (3), 2000, pp.124-130.

[4] Daly, C., Pachler, N. and Lambert, D. 'Teacher learning: towards a professional academy'. Teaching in Higher Education, 2004 vol 9 (1).

[5] DfES. Teachers' standards framework : helping you develop. Department for Education and Skills, London, 2001.

[6] Fisher, Higgins and Loveless, 2006 Fisher, T., Higgins, C. and Loveless, A., (2006). Teachers learning with Digital Technologies: A review of research and projects: Futurelab.

[7] Garrison, D. and Anderson, T. E-Learning in the 21st Century: A Framework for Research and Practice. RoutledgeFalmer, London, 2003.

[8] Garrison, D., Anderson, T. and Archer, W. 'Critical thinking, cognitive presence and computer conferencing in distance education'. American Journal of Distance Education, 15 (1), 2001, pp.7-23.

[9] Haggarty et al., (2011) Haggarty, L., Postlethwaite, K., Diment, K. and Ellins, J. (2011). 'Improving the learning of newly qualified teachers in the induction year'. British Educational Research Journal, 37 (6), 935-954.

[10] Hargreaves, A. The persistence of presentism and the struggle for lasting improvement, UCL Institute of Education, University of London, 2008.

[11] Laurillard, D., (2009). 'The pedagogical challenges to collaborative technologies'. Journal International Journal of Computer-Supported Collaborative Learning 4 (1), 5-20.

[12] Lave, J. and Wenger, E. Situated Learning: Legitimate Peripheral Participation, Cambridge University Press, Cambridge, 1991.

[13] Mason, J. Qualitative Researching, Sage, London, 1996.

[14]Mishra, P. and Koehler, M. J., (2006). 'Technological Pedagogical Content Knowledge: A Framework for Teacher Knowledge'. Teachers College Record, 108 (6), 1017-1054.

[15] Moore, A. The Good Teacher: Dominant discourses in teaching and teacher education, Routledge, London, 2004.

[16] Oliver, M., (2003). 'Looking Backwards, Looking Forwards: An overview, Some Conclusions and an Agenda'. In J. Seale (Ed.), Learning technology in transition : from individual enthusiasm to institutional implementation (pp. 166). Lisse ; Abingdon: Swets and Zeitlinger 
[17] Quarshie, R. Classroom Interactions: The complexity of the classroom. Master of Teaching (MTeach) VLE: Institute of Education, 2015.

[18] Tickle, L. Teacher induction: the way ahead, Open University, Buckingham, 2000.

[19] Yandell, J., (2010). 'Sites of Learning', Critical practice in teacher education : a study of professional learning (pp. 15-28). London: Institute of Education University of London 